See Article page 1138

\section{Commentary: Bridge to bridge: No longer a bridge too far for successful cardiac transplant}

\author{
Darshan H. Brahmbhatt, MA, MB BChir, ${ }^{a, b, c}$ and \\ Vivek Rao, MD, $\mathrm{PhD}^{\mathrm{a}, \mathrm{d}}$
}

Cardiogenic shock (CS) is a condition characterized by impaired cardiac output and end-organ hypoperfusion that results in significant morbidity and mortality. It remains the leading cause of death after acute myocardial infarction and despite improvements in CS management, mortality remains high, at $30 \%$ to $50 \%$ in contemporary registries. ${ }^{1}$ Treatment strategies include improving cardiac performance by administration of vasoactive medications, but often these are insufficient and mechanical circulatory support (MCS) is required to improve end-organ perfusion and rest the failing myocardium. The use of venoarterial extracorporeal membrane oxygenation (VA-ECMO) has increased in recent times to provide biventricular support in patients with severe CS. It provides hemodynamic support to patients, allowing oxygenation and removal of carbon dioxide. Nevertheless, this is only a short-term solution because patients frequently develop complications when supported on VA-ECMO, increasing with each additional day on support. The aim is often that VA-ECMO is used as a bridge to recovery, with sufficient time on support allowing the underlying cardiac dysfunction to improve. If this does not occur, VA-ECMO may be used as a bridge to cardiac transplantation (BTT), or alternatively as a bridge to another more durable MCS device, a bridge-to-bridge

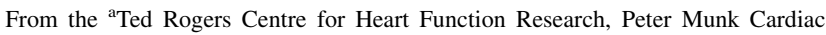
Centre, University Health Network, Toronto, Ontario, Canada; Divisions of ${ }^{\mathrm{b}}$ Cardiology and ${ }^{\mathrm{d}}$ Cardiovascular Surgery, University of Toronto, Toronto, Ontario, Canada; and ${ }^{c}$ National Heart \& Lung Institute, Imperial College London, London, United Kingdom.

Disclosures: Dr Rao is a consultant to Abbott and Medtronic and Dr Brahmbhatt is supported by an educational award from Transform HF.

The Journal policy requires editors and reviewers to disclose conflicts of interest and to decline handling or reviewing manuscripts for which they may have a conflict of interest. The editors and reviewers of this article have no conflicts of interest.

Received for publication Sept 23, 2021; revisions received Sept 23, 2021; accepted for publication Sept 24, 2021; available ahead of print Sept 29, 2021.

Address for reprints: Vivek Rao, MD, PhD, Division of Cardiovascular Surgery University Health Network, 4PMB 457, 200 Elizabeth St, Toronto, Ontario M5G 2C4,

Canada (E-mail: Vivek.Rao@uhn.ca).

J Thorac Cardiovasc Surg 2023;165:1149-50

$0022-5223 / \$ 36.00$

Copyright (c) 2021 by The American Association for Thoracic Surgery

https://doi.org/10.1016/j.jtcvs.2021.09.041

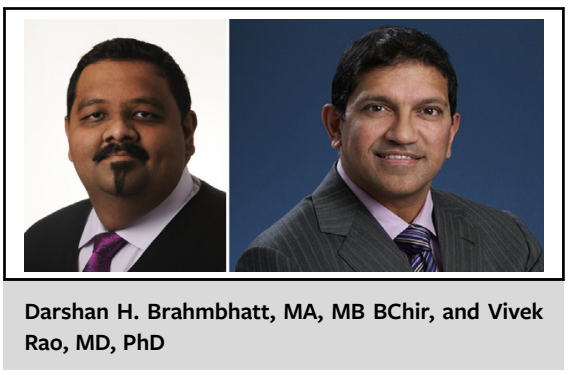

CENTRAL MESSAGE

In patients with cardiogenic

shock with biventricular failure

supported on venoarterial

ECMO, Total Artificial Heart im-

plantation can be used as a suc-

cessful bridge to transplant.

(BTB) strategy, allowing more time for either recovery or for a suitable donor organ to become available. ${ }^{2}$

In their study, Noly and colleagues ${ }^{3}$ describe a multicenter, observational, North American experience of using the Total Artificial Heart (TAH) (SynCardia Systems, Tucson, Ariz) device as a temporary BTT after liberation from VA-ECMO. ${ }^{3}$ The study reports on 54 patients who were supported with this sequential BTB strategy, comparing them with 163 patients who were supported with TAH alone as BTT. Despite BTB, patients having higher acuity (all were INTERMACS profile 1) before TAH implantation, important clinical outcomes, including discharge from hospital $(32 \%$ vs $37 \% ; P=.09)$, survival to transplant $(59 \%$ in BTB vs $65 \%$ in TAH alone group; $P=.44$ ), and survival after transplantation $(87 \%$ vs $83 \% ; P=.82)$ were similar in those patients to those supported with TAH alone. Median time of support on TAH was 3.0 months.

The authors should be congratulated for demonstrating the feasibility of bridging patients supported with VAECMO to transplantation using TAH. Patients with biventricular dysfunction have fewer options for support, with biventricular ventricular assist device (VAD) the only alternative to TAH for longer-term BTT. The authors compare these 2 strategies in their discussion, but registry data are not sufficiently granular to afford a meaningful comparison-the International Society for Heart and Lung Transplantation Registry for Mechanically Assisted Circulatory Support analyses include various configurations of both temporary and durable VAD. ${ }^{4}$ Another concern is volume 
of TAH implantation. In this study, 2 centers performed the bulk of TAH procedures, with the other 4 centers implanting fewer than 5 devices per year. There is robust evidence suggesting that very-low implanting centers (implanting fewer than 10 durable VADs) have poorer outcomes when compared with more experienced centers. ${ }^{5}$ It may be that a similar volume of surgeries is required to maintain competence in TAH implantation too. Finally, it is unclear if the 2 high-volume centers use TAH preferentially as their MCS device of choice, even when durable left VAD with temporary right-sided support may be an option, which may add further bias into patient selection across different study locations.

Nevertheless, despite limitations associated with observational studies, this report significantly contributes to the understanding of feasible options for patients in CS supported with VA-ECMO who may not be immediately suitable for transplantation or may need to wait for a suitable donor organ to become available. The challenge for clinicians in the field remains choosing which strategy and device is best suited to individual patients; a challenge that is yet to be overcome.

\section{References}

1. Papolos AI, Kenigsberg BB, Berg DD, Alviar CL, Bohula E, Burke JA, et al. Management and outcomes of cardiogenic shock in cardiac ICUs with versus without shock teams. J Am Coll Cardiol. 2021;78:1309-17.

2. Brahmbhatt DH, Daly AL, Luk AC, Fan E, Billia F. Liberation from venoarterial extracorporeal membrane oxygenation: a review. Circ Heart Fail. 2021;14:e007679.

3. Noly P-E, Moriguchi J, Shah KB, Anyanwu AC, Mahr C, Skipper E, et al. A bridge-to-bridge approach to heart transplantation using extracorporeal membrane oxygenation and total artificial heart. J Thorac Cardiovasc Surg. 2023;165: 1138-48.e1.

4. Ton VK, Xie R, Hernandez-Montfort JA, Meyns B, Nakatani T, Yanase M, et al. Short- and long-term adverse events in patients on temporary circulatory support before durable ventricular assist device: an IMACS registry analysis. J Heart Lung Transplant. 2020;39:342-52.

5. Cowger JA, Stulak JM, Shah P, Dardas TF, Pagani FD, Dunlay SM, et al. Impact of center left ventricular assist device volume on outcomes after implantation: an INTERMACS analysis. JACC Heart Fail. 2017;5:691-9. 